\title{
CD68 reactivity of non-macrophage derived tumours in cytological specimens
}

\author{
I A Doussis, K C Gatter, D Y Mason
}

\begin{abstract}
Aims-To investigate the presence of the macrophage associated antigen CD68 in non-haematopoietic tumours.

Methods-Cytological specimens from non-macrophage derived tumours were stained using the alkaline phosphatase anti-alkaline phosphatase immunocytochemical method (APAAP) and three monoclonal anti-CD68 antibodies, Y1/82A, EBM11, and KP1.

Results-Reactivity of malignant cells with one or more of the antibodies was seen in 11 out of 40 adenocarcinomas and in one of seven poorly differentiated carcinomas; other neoplasms, including 10 cases of squamous carcinoma, three of malignant melanoma, and four of oat cell carcinoma were negative. Monoclonal antibody KP1 gave the strongest staining and reacted with the highest proportion of neoplastic cells.

Conclusions-CD68 is expressed in a proportion of epithelial tumours although the labelling is usually less intense than in macrophages. Anti-CD68 antibodies should therefore be used as part of a panel in the diagnosis of poorly differentiated neoplasms in cytological material.
\end{abstract}

(F Clin Pathol 1993;46:334-336)

At the Fourth International Workshop on Human Leucocyte Differentiation Antigens (Vienna 1989), five different monoclonal antibodies were identified as pan-macrophage reagents recognising a 110 kilodalton glycoprotein and were designated as a new CD group CD68.

CD68 is the most macrophage-monocyte specific group of markers identified to date. In a detailed study of its distribution, however, small amounts were found in lymphocytes and in non-haematopoietic cells, such as renal tubules, and additionally it was detected in the vulval carcinoma cell line A431 and the melanoma cell line RVH421.2

Immunocytochemistry can be particularly useful in resolving diagnostic problems relating to tumours of uncertain origin. ${ }^{3}$ In cytological specimens in particular, the need for accurate and objective characterisation of small groups of cells frequently arises, because the amount of material available is often limited or of suboptimal quality. In these cases a panel of monoclonal antibodies can be crucial for the correct characterisation of a poorly differentiated neoplasm. It is therefore essential that the monoclonal antibodies used are well characterised and that the full spectrum of cell types which they recognise is known, to avoid misleading interpretations.

This study was undertaken to investigate how specific the CD68 antigen is for cells of monocyte-macrophage origin in cytological samples, and hence to establish its diagnostic value in this context.

\section{Methods}

Sixty eight cytological specimens were examined; 16 of ascitic fluid, eight of pleural fluid, six fine needle aspirates of the breast, five fine needle aspirates of the liver, two fine needle aspirates of the pancreas, two fine needle aspirate of the lung, three fine needle aspirates from lymph nodes, one fine needle aspirate from the kidney and one from the prostate, one specimen of mid-stream urine and 23 fine needle aspirates from various sites of the body.

All specimens were received unfixed. Wet fixed as well as air dried smears were prepared, stained with the Papanicolaou and the Romanowsky methods, respectively, and processed for routine cytological diagnosis. Spare unfixed smears were prepared and stored at $-20^{\circ} \mathrm{C}$.

Three monoclonal antibodies that recognise the CD68 antigen were used. Monoclonal antibody Y1/82A was raised against phytohaemagglutinin activated peripheral blood monocytes, ${ }^{4}$ antibody $\mathrm{KP1}$ against a lysosomal fraction of human lung macrophages, ${ }^{5}$ and antibody EBM 11 against isolated human lung macrophages. ${ }^{6}$ All antibodies were applied as undiluted tissue culture supernatant fluids.

An alkaline phosphatase anti-alkaline phosphatase (APAAP) immunocytochemical method was used, as described previously. The alkaline phosphatase substrate was prepared with naphthol AS-MX phosphate (Sigma Catalogue No 4875) and Fast Red TR salt (Sigma Catalogue No F1500), and contained Levamisole to block endogenous enzyme activity.

\section{Results}

All three antibodies showed strong punctate cytoplasmic staining of all macrophages present in the samples studied (figs $1 \mathrm{~A}, \mathrm{D}$ ), as
Correspondence to: Dr KC Gatter 
Figure 1 $(A)$

Adenocarcinoma negative for KP1. The macrophages present in the field are an internal positive control.

(B) Dot-like reactivity in mucin-containing tumour cells (arrow).

(C) Pancreatic

adenocarcinoma with dotlike positivity in the

tumour cells (arrow).

Note, however, the

difference in the strength of

reaction between the

macrophages and the

tumour cells. (D) Renal

cell carcinoma with dot-

like and diffuse reactivity.

(E) Diffuse reactivity in

this group of tumour cells

that was consistent with a

bladder primary.

(F) Melanoma cells were negative for both KP1 and Y1/82A antibodies.

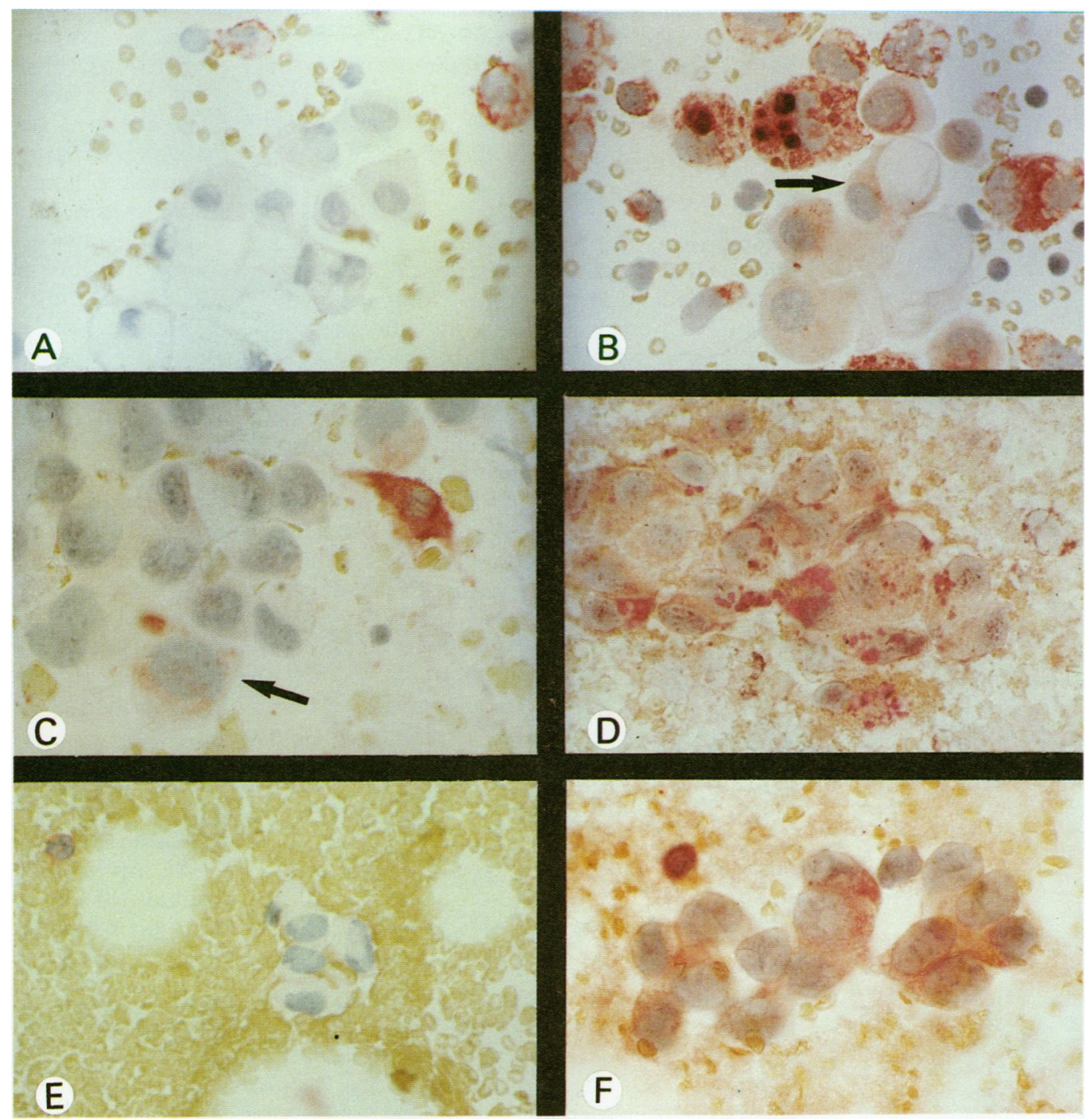

previously reported. ${ }^{2} \mathrm{KP1}$ also stained neutrophils; EBM11 reacted only weakly and Y1/82A not at all with these cells. No reactivity of lymphocytes was observed. The staining patterns of the three anti-CD68 monoclonal antibodies are summarised in the table.

Eleven adenocarcinomas out of 40 showed reactivity for $\mathrm{CD} 68$ with at least one of the

Results of anti-CD68 monoclonül antibodies

\begin{tabular}{|c|c|c|c|}
\hline Cases & $Y 1 / 82 A$ & $E B M 11$ & $K P 1$ \\
\hline \multicolumn{4}{|l|}{ Adenocarcinomas } \\
\hline Ovarian & $0 / 6$ & $0 / 3$ & $0 / 5$ \\
\hline Endometrial & $0 / 2$ & $0 / 1$ & $0 / 1$ \\
\hline Pancreatic & $1 / 4$ & $1 / 1$ & $2 / 2$ \\
\hline Prostatic & * & $\star$ & $0 / 2$ \\
\hline Gastrointestinal & $0 / 2$ & $0 / 1$ & $0 / 1$ \\
\hline Thyroid & $0 / 2$ & $\star$ & $0 / 1$ \\
\hline Renal & $0 / 1$ & $\star$ & $1 / 1$ \\
\hline \multicolumn{4}{|l|}{ Breast } \\
\hline ductal & $0 / 5$ & $1 / 1$ & $1 / 5$ \\
\hline lobular & $\star$ & $\star$ & $1 / 1$ \\
\hline Unknown origin & $2 / 14$ & $0 / 6$ & $5 / 14$ \\
\hline $\begin{array}{l}\text { Squamous cell } \\
\text { carcinoma }\end{array}$ & $0 / 7$ & $0 / 4$ & $0 / 9$ \\
\hline Oat cell carcinoma & $0 / 4$ & $0 / 3$ & $0 / 3$ \\
\hline Malignant melanoma & $0 / 2$ & $\star$ & $0 / 1$ \\
\hline Testicular tumour & $0 / 1$ & $\star$ & $\star$ \\
\hline $\begin{array}{l}\text { Transitional cell } \\
\text { carcinoma }\end{array}$ & $0 / 1$ & $\star$ & $0 / 1$ \\
\hline Angiosarcoma & $0 / 1$ & $\star$ & $0 / 1$ \\
\hline $\begin{array}{l}\text { Poorly differentiated } \\
\text { carcinoma }\end{array}$ & $0 / 7$ & $0 / 5$ & $1 / 7$ \\
\hline
\end{tabular}

*no material available monoclonal antibodies used. In the positive cases staining ranged from a few positive dots in occasional cells to moderate staining of a large number of tumour cells (fig 1B). This latter pattern was particularly noticeable in three pancreatic carcinomas (fig 1C).

In the case of renal cell carcinoma (fig 1D), KP1 antibody showed a strong, diffuse pattern of reactivity in a small number of unreactive.

In one of the five cases of ductal and the single case of lobular carcinoma of the breast scattered tumour cells with dot-like positivity were identified with KP1 and EBM11, while Y1/82A showed no reactivity.

Overall, monoclonal antibody $\mathrm{KP} 1$ reacted more intensely with the tumour cells and stained a larger number of them than either of the other two antibodies. The staining pattern is usually seen as a variable number of intracytoplasmic granules, with only occasional cases showing a diffuse cytoplasmic reactivity. The pattern of staining was, however, consistently less intense than that observed in macrophages and granulocytes.

Of the seven poorly differentiated carcinoto have arisen from the bladder, showed cytoplasmic reactivity as well as a dot-like cells. Antibody Y1/82A, in contrast, was mas, one case considered on clinical grounds 
intense, diffuse cytoplasmic staining with $\mathrm{KP1}$ (fig 1E). All 10 cases of squamous carcinoma, four of oat cell carcinoma, three of malignant melanoma, and single cases of testicular tumour, transitional cell carcinoma, and angiosarcoma were negative (fig $1 F$ ).

\section{Discussion}

The CD68 antigen characteristically shows a strong granular distribution within the cytoplasm of macrophages and monocytes. ${ }^{2}$ Monoclonal anti-CD68 antibodies (Y1/82A, $\mathrm{Y} 2 / 131, \mathrm{KP} 1, \mathrm{EBM} 11, \mathrm{Ki}-\mathrm{M} 6$ and $\mathrm{Ki}-\mathrm{M} 7$ ) do, however, show subtle differences in their immunocytochemical reactivity and Pulford et $a^{2}$ have speculated that this may be due to differences in glycosylation of the molecule between cell types. Furthermore, a detailed study of the distribution of CD68 antigen showed that some of the antibodies stain cells other than macrophages, including nonhaematopoietic cells, as well as carcinoma and melanoma cell lines. ${ }^{2}$

In this study, we have shown that CD68 antigen is expressed in carcinomas when studied in cytological samples.

Y1/82A was initially described as reacting with a wide spectrum of cells from the monocyte-macrophage system and to be entirely negative on neoplastic cells from squamous carcinoma and adenocarcinoma of the breast. ${ }^{4}$ It has been shown to be useful in identifying cases of M4 and M5 acute myeloid leukaemia, ${ }^{8}$ but it has also been reported to react with normal hepatocytes, as well as with a vulval carcinoma and melanoma cell line. ${ }^{2}$ In our series, in one of the cases of pancreatic carcinoma and two cases of adenocarcinoma of unknown origin, a few neoplastic cells showed scattered intracytoplasmic granular staining.

EBM11 has been reported to react with both the acini and the islets of the pancreas, ${ }^{2}$ so that the positivity seen in the current study in neoplastic epithelial cells was not entirely unexpected, although it has not been reported previously.

KP1 recognises a fixation resistant epitope of the CD68 antigen in paraffin wax embedded material. ${ }^{5}$ It has been used in previous studies to quantitate infiltrations of reactive macrophages in malignant tumours ${ }^{9}$ and to differentiate myelomonocytic and macrophage neoplasms from other tumours of similar appearance. ${ }^{10}$ It has also been used to identify normal and neoplastic mast cells. ${ }^{11}$ When KP1 was tested in frozen material, it was expressed in hepatocytes, tubules in the kidney, islets of Langerhans in the pancreas and endothelium, and connective tissue of various organs, as well as in cells of monocyte macrophage lineage and neutrophils.' Therefore, the positivity of several epithelial tumour cells in both cases of pancreatic carcinoma and of all the tumour cells in the case of renal cell carcinoma was not unprecedented. Cross-reactions of other monocytemacrophage antibodies with renal tubules have been reported ${ }^{12}$ and in particular Kaiser et $a l^{13}$ reported two monocyte-macrophage associated antibodies, $\mathrm{Ki}-\mathrm{M} 3$ and $\mathrm{Ki}-\mathrm{M} 7$ (anti-CD 68), that reacted with all 19 cases of renal cell carcinomas which they studied. $\mathrm{KP} 1$ has also been reported to react with malignant melanomas ${ }^{14}$ and granular cell neoplasms, ${ }^{15}$ although the single case that we studied was negative.

The reactivity with epithelial cells varied among the three monoclonal antibodies, with Y1/82A staining fewer cases more weakly than either KP1 or EBM11. Overall, macrophage staining was much more prominent with all antibodies than was the staining of the tumour cells so that it was usually possible to differentiate the two cell types.

These results indicate that, although CD68 is a robust macrophage marker, immunocytochemical staining results on cytological specimens must be interpreted with caution. If possible, anti-CD68 reagents should be used in combination with other myeloid and antimacrophage antibodies as part of a panel of antibodies to eliminate the possibility of misidentifying particular cell types.

We thank $\mathrm{Dr} W$ Gray for providing the cytological material, Dr $\mathrm{K}$ Pulford for helpful discussions regarding the CD68 reactivity, and Mrs F Williams for excellent secretarial assistance.

Financially supported in part by the Oxfordshire Health Authority.

Dako Ltd generously paid for the colour work.

1 Micklem K, Rigney E, Cordell J, et al. A human macrophage-associated antigen (CD68) detected by six different monoclonal antibodies. $\mathrm{Br} \quad \mathcal{F}$ Haemato 1989;73:6-11.

2 Pulford KAF, Sipos A, Cordell JL, Stross WP, Mason DY. Distribution of the CD68 macrophage/myeloid associated antigen. Int Immunol 1990;2:973-80.

3 Mason DY, Gatter KC. The role of immunocytochemistry in diagnostic pathology. $f$ Clin Pathol 1987; chemistry in

4 Davey FR, Cordell JL, Erber WN, Pulford KAF, Gatter KC, Mason DY. Monoclonal antibody (Y1/82A) with specificity towards peripheral blood monocytes and tissue macrophages. F Clin Pathol 1988;41:753-8.

5 Pulford KAF, Rigney EM, Micklem KJ, et al. KP1: a new monoclonal antibody that detects a monocyte macrophage associated antigen in routinely processed tissue sections. F Clin Pathol 1989;42:414-21.

6 Kelly PMA, Bliss E, Morton JA, Burns J, McGee JO. Monoclonal antibody EBM/11: high cellular specificity for human macrophages. 7 Clin Pathol 1988;41:510-15.

7 Cordell JL, Falini B, Erber WN, et al. Immunoenzymatic labeling of monoclonal antibodies using immune complexes of alkaline phosphatase and monoclonal antiplexes of alkaline phosphatase and monoclonal anti-
alkaline phosphatase (APAAP complexes). $\mathcal{J}$ Histochem alkaline phosphatase (APAAP

8 Davey FR, Erber WN, Gatter KC, Mason DY. The use of monoclonal antibody $\mathrm{Y} 1 / 82 \mathrm{~A}$ in the identification of acute myeloblastic and monocytic leukaemias. $\mathrm{Am} \mathcal{F}$ Clin Pathol 1988;89:76-80.

9 Rossi M, Buller J, Heath S, et al. The monocyte/ macrophage infiltrate in 35 medulloblastomas: a paraffin-wax study. Tumori 1991;77:36-40.

10 Warnke RA, Pulford KAF, Pallesen G, et al. Diagnosis of myelomonocytic and macrophage neoplasms in routinely processed tissue biopsies with monoclonal routinely processed tissue biopsies with mo
antibody KP1. Am ₹ Pathol 1989;135:1089-95.

11 Horny H-P, Schaumburg-Lever G, Bolz S, Geerts ML, Kaiserling E. Use of monoclonal antibody KP1 for idenKaiserling E. Use of monoclonal antibody KP1 for identifying normal and neo

12 Radzun HJ, Parwaresch MR. Differential immunohistochemical resolution of the human mononuclear phagocyte system. Cell Immunol 1983;82:174-83.

13 Kaiser U, Hansmann M-L, Papadopoulos I, Radzun HJ. Monocyte/macrophage-directed antibodies $\mathrm{Ki}-\mathrm{M} 3$ and $\mathrm{Ki}$-M7 detect renal cell carcinomas. Int $\mathcal{F}$ Cancer 1988 (Supplement 3):45-9.

14 Facchetti F, Bertalot G, Grigolato PG. KP1 (CD 68) staining of malignant melanomas. Histopatholog' 1991; 19:141-5.

15 Tsang WYW, Chan JKC. KP1 (CD 68) staining of granular cell neoplasms: is KP1 a marker for lysosomes rather than the histiocytic lineage? Histopathology' 1992;21: 84-6. 